\title{
Reproducibility in animal models of hypertension: a difficult problem
}

\author{
Jane F. Reckelhoff ${ }^{1,3,4^{*}}$ and Barbara T. Alexander ${ }^{2,3,4}$
}

\begin{abstract}
In 2016, the National Institutes of Health mandated that all grant proposals enhance reproducibility through rigor and transparency. In the past few years, physiological outcomes in established animal models of hypertension, in particular in regard to sex differences, have varied from study to study or laboratory to laboratory. The aim of this commentary is to increase investigator awareness of caveats related to animal models that may be sensitive to vendor-, barrier-, or diet-specific changes that result in an inability to sustain the genotype and/or phenotype of well-established experimental models. These considerations are critical in order for investigators to make informed and educated decisions in regard to their hypothesis-driven research, in particular as it relates to experimental design and interpretation, and the reporting of results.
\end{abstract}

Keywords: Dahl salt-sensitive rat, Spontaneously hypertensive rat, Rag-1 knockout mouse

In January 2016, the National Institutes of Health (NIH) mandate for Rigor and Reproducibility took effect for all research grants and mentored career development award applications. These guidelines were based on data presented in 2014 at a conference at the NIH that was jointly sponsored by Nature/Science journals on the issue of reproducibility and rigor in preclinical research findings. As a result, many journals and journal editors also signed off on the guidelines to support preclinical research that is "reproducible, robust, and transparent.". However, in recent years, animal models that have been historically used for the study of the mechanisms responsible for hypertension have undergone changes in genotype and/or phenotype compromising the ability of investigators to maintain reproducibility.

For example, in 2016, Zimmerman and Lindsey pointed out in a Letter to the Editor of the American Journal of Physiology Renal Physiology a shift in blood pressure in female Dahl salt-sensitive (DS) rats kept on a low-salt diet [1]. Their observations included a study by Gillis et al. published in 2015 that reported female DS rats descended from the original Rapp strain maintained

\footnotetext{
* Correspondence: jreckelhoff@umc.edu

${ }^{1}$ Department of Cell and Molecular Biology, University of Mississippi Medical Center, Jackson, USA

${ }^{3}$ Mississippi Center of Excellence in Perinatal Research, University of

Mississippi Medical Center, Jackson, USA

Full list of author information is available at the end of the article
}

at the University of Mississippi Medical Center and fed a $0.3 \% \mathrm{NaCl}$ phytoestrogen replete diet had a mean arterial pressure (MAP) of $155 \mathrm{mmHg}$ at approximately 17 weeks of age [2]. MAP in this study was measured by radiotelemetry, the gold standard for recording of arterial pressure in rodents [3]. Yet, Brinson and colleagues reported that MAP was $125 \mathrm{mmHg}$ at 16 weeks of age in DS females obtained from the breeding colony at Georgia Regents, now Augusta University, and fed a $0.4 \% \mathrm{NaCl}$ phytoestrogen-free diet [4]. Blood pressure in this study was also measured via telemetry [4]. Zimmerman and Lindsey also included studies from their own laboratory demonstrating DS rats from Harlan (now Envigo) or Charles River placed on a $0.3 \% \mathrm{NaCl}$ phytoestrogen replete diet, or fed a $0.3 \%$ or $0.5 \% \mathrm{NaCl}$ phytoestrogen free diet, exhibited a significant difference in systolic blood pressure (SBP) at 15 to 16 weeks of age measured by tail cuff in the conscious state, a difference of $200 \mathrm{mmHg}$ versus 155-170, respectively [1]. These differences in blood pressure in female DS rats occurred despite the potential for a phytoestrogen-free diet to increase BP compared to a diet containing phytoestrogens, although this effect could be sex and age-dependent $[5,6]$. Our laboratory reported in 2016 that MAP in 16-week-old DS female rats obtained from Harlan (now Envigo) and fed a $0.3 \% \mathrm{NaCl}$ phytoestrogen replete diet was also $155 \mathrm{mmHg}$ [7], whereas MAP in a study from our laboratory in 2010 was only 105 
$\mathrm{mm} \mathrm{Hg}$ [8]. Both studies were performed in female DS rats obtained from the same vendor; however, the study published in 2010 was performed in female rats at 10 weeks of age that were fed a $0.3 \%$ phytoestrogen, nitrate/nitrite-free diet. In our 2010 study, MAP was similar in intact female DS relative to ovariectomized (OVX) DS maintained on a low-salt diet [8]. However, when placed on a high salt diet $(8 \% \mathrm{NaCl}), \mathrm{MAP}$ in OVX DS rats was significantly more salt-sensitive (i.e., increased to a greater degree) than intact female DS on high salt [8]. Greater salt sensitivity was also reported in OVX DS in the study published by Brinson et al. [4]. However, exposure to a high salt diet (8\%) did not further increase SBP in intact or OVX DS rats as reported by Zimmerman and Lindsey [1]. Based on our previous data, and those of many others, one would expect a consistent salt-sensitive increase in blood pressure in OVX DS rats on a high-salt diet. Collectively, based on these observations, Zimmerman and Lindsey concluded that greater transparency was needed from both commercial vendors and from investigators. We agree and conclude that the published differences certainly suggest there may be genomic differences impacting the phenotype drifts in blood pressure in the DS rat strain. It is important to note that as far back as 2005, Mattson et al. demonstrated that the blood pressure response in sodium-dependent hypertension in the DS rat is nutrient specific with the dietary source of protein playing an important role in the development of hypertension in the DS rat [9]. Clearly, this study from the Mattson laboratory highlights the importance of biological variables including dietary components on physiological outcomes.

In 2018, Pai and colleagues reported that DS females exhibit spontaneous hypertension when maintained on a low-salt (0.1\%), phytoestrogen replete (Teklad) diet [10]. In addition, OVX at 3 months of age had no effect on MAP or body weight by 7 months of age, and MAP averaged $160-163 \mathrm{mmHg}$ in intact and DS rats, respectively [10]. They also found that OVX at 6 weeks of age (prepubertal) had no effect on MAP by 10 months of age, compared to intact females [10]. These investigators went on to compare the genetics of the SS/JrHsd/Env (the Envigo DS rats) with the SS/Jr (the original Rapp strain maintained at University of Toledo) and the SS/JrHsd/ Mcwi strain maintained at the Medical College of Wisconsin [10]. While complete direct genomic comparisons were not feasible, they reported more single nucleotide polymorphisms and insertion-deletion polymorphisms in SS/JrHsd/Env than in the SS/JrHsd/Mcwi and SS/Jr. They also showed more genetic variants when comparing the $\mathrm{SS} / \mathrm{JrHsd} / \mathrm{Env}$ than in the other two strains. In addition, $\mathrm{SS} / \mathrm{JrHsd} / \mathrm{Env}$ had a greater number of heterozygous/ homozygous ratios than the other two strains [10].

The Rag1 ${ }^{-1-}$ mouse on a C57Bl/6 J background is another example of divergence in observed physiological outcomes. The Rag1 $1^{-1-}$ mouse is $\mathrm{T}$ cell deficient due to a targeted mutation of the recombination-activating gene-1 (Rag1) [11]. In 2007, Guzik and colleagues reported that $\operatorname{Rag} 1^{-/}$mice had no pressor response (no increase in blood pressure) to high doses of angiotensin (Ang) II [12]. Over the subsequent years, studies similar to these, using similar doses of Ang II, were repeated by four additional laboratories with similar results [13-16]. However, in 2017, Ji and colleagues reported that MAP in the Rag1 ${ }^{-/-}$mice was no longer refractory to Ang II [17] and that the pressor response to even a low dose of Ang II, $490 \mathrm{ng} / \mathrm{kg}$, was similar between the Rag1 $1^{-/-}$mice and wild-type mice. The subsequent increase in MAP in response to Ang II in $\operatorname{Rag} 1^{-1-}$ was shown to be independent of T cells in this study [17].

In 2014, Taconic Laboratories stopped providing the spontaneously hypertensive rats (SHR). Prior to this time, we noticed that one or both kidneys of approximately $40 \%$ of both male and female SHR exhibited increased hydronephrosis, often with little medulla present (unpublished findings). We contacted the company with pictures of the kidneys and subsequently moved away from using these animals. This was difficult for us since we had been using this strain and vendor source for these animals to study sex differences in blood pressure regulation both in young adult animals and in rats aged up to 20 months, since the mid-late 1990s, and had more than 40 publications with them. In order to continue studies in this rat stain with another vendor, we are repeating even the simplest studies, such as the effect of sex steroids on blood pressure, to validate our earlier findings. It is important to note that the SHR is a commonly used animal model of essential hypertension. While we reported that antioxidants like tempol reduce MAP in male SHR, but have little effect in female SHR at 12 weeks of age [18], a new study by Gillis and colleagues using the Envigo SHR showed no effect of tempol on MAP in male or female SHR at 12 weeks of age when measured with telemetry [19]. These findings are also contrary to studies by others that report a significant reduction in MAP in tempol-treated male SHR [20, 21].

Taken together, these studies indicate that while the ability to reproduce studies of other investigators, or studies performed even within our own laboratories, is an important and laudable goal, it may be hampered from year to year due to diverging genomics that affect the phenotype of the experimental animal models. This is especially important for the study of sex differences in biological systems. For example, we now know that diet plays a huge role in mediating sex differences, since new data show that the microbiome affects the levels of sex steroids [22]; thus, sex steroid-mediated responses can change with different diets. Vendors must be cognizant of this and remain transparent in their reporting of 
change in diets to investigators that utilize these experimental rodent strains. Investigators should also be diligent and aware of the effect that relevant biological variables such as diet, vendor, or source including changes in commercial barrier may have on their predicted or expected outcomes.

Thus, the recent mandate by NIH in regard to consideration of relevant biological variables is timely. Consideration of relevant biological variables is critical in order to maintain rigor and reproducibility in animal studies and resides not only with the investigator, but also with the vendors who provide the experimental animal models and rodent strains used by numerous scientists. In a perfect world, vendors are expected to maintain the quality of their rodent strains. They should hold to a high level of transparency by providing information on their websites any time they make any changes that could impact the genotype/phenotype of their animals. Maintenance of these experimental models and rodent strains should also include routine genotyping. Vendors would likely argue that this would be prohibitively expensive and thus not feasible. In addition, most vendors change husbandry, breeding, feeding, and maintenance protocols to become more cost-efficient. Unfortunately, they do so in most cases without informing the investigators who spend large sums of money and depend on these animals to remain consistent over long periods of time. Having investigators go to the expense and work of maintaining their own colonies is also not the solution since it defeats the purpose of having commercial vendors to supply large numbers of animals that are consistent as possible in their genotype and phenotype in order to reinforce reproducibility of scientific findings. It is also imperative that investigators promote reproducibility by providing as much detail as possible regarding husbandry, diet, and housing conditions of the animals being studied, include explicit information on the methods used and as noted in the mandate by the NIH, and subscribe to a high level of rigor in their experimental design and reporting of results.

This commentary was written to raise awareness regarding the frustration of scientists in their inability to reproduce blood pressure data in commonly used experimental animal models and the subsequent studies some investigators have performed to investigate why this is occurring. This commentary should serve as an alert to others that their experimental animal models or systems may be changing with time. We provide no solutions to the problem of changing genotypes/phenotypes in the models we typically use, but believe that rigor and reproducibility is still the ultimate goal. Investigators need to determine what animal model will best allow them to address their hypotheses, with the caveat that some of their results may not be exactly as they or others have previously published. Publication of these differences is imperative in order to ensure the ongoing documentation of the effect of biological variables on experimental outcomes.

\section{Acknowledgements}

This work is supported by NIH grants R01HL66072, R01HL67028, P01HL51971 (to JFR) and R56HL143459 and P01HL51971 (to BTA). Research reported in this publication was supported by the National Institute of General Medical Sciences of the National Institutes of Health under Award Number P20GM121334 (JFR) and P20GM104357. The content is solely the responsibility of the authors and does not necessarily represent the official views of the National Institutes of Health.

\section{Funding}

Stated in Acknowledgements

Availability of data and materials

Not applicable

\section{Authors' contributions}

JFR researched PubMed and wrote the manuscript. BTA edited the manuscript. Both authors read and approved the final manuscript.

Ethics approval and consent to participate

Not applicable

Consent for publication

Approved by authors

Competing interests

The authors declare that they have no competing interests.

\section{Publisher's Note}

Springer Nature remains neutral with regard to jurisdictional claims in published maps and institutional affiliations.

\section{Author details}

'Department of Cell and Molecular Biology, University of Mississippi Medical Center, Jackson, USA. ${ }^{2}$ Department of Physiology, University of Mississippi Medical Center, Jackson, MS 39216-4505, USA. ${ }^{3}$ Mississippi Center of Excellence in Perinatal Research, University of Mississippi Medical Center, Jackson, USA. ${ }^{4}$ Women's Health Research Center, University of Mississippi Medical Center, Jackson, MS 39216-4505, USA.

Received: 16 August 2018 Accepted: 11 December 2018

Published online: 22 December 2018

\section{References}

1. Zimmerman MA, Lindsey SH. Inconsistent blood pressure in female Dahl salt-sensitive rats. Am J Physiol Renal Physiol. 2016;311:F1391-2.

2. Gillis EE, Williams JM, Garrett MR, Mooney JN, Sasser JM. The Dahl salt sensitive rat is a spontaneous model of superimposed preeclampsia. Am J Physiol Regul Integr Comp Physiol. 2015;309:R62-70.

3. Van Vliet BN, McGuire J, Chafe L, Leonard A, Joshi A, Montani JP. Phenotyping the level of blood pressure by telemetry in mice. Clin Exp Pharmacol Physiol. 2006;33(11):1007-15.

4. Brinson KN, Rafikova O, Sulllivan JC. Female sex hormones protect against salt-senstive hypertension but not essential hypertension. Am J Physiol Regul Integr Comp Physiol. 2014;307:R149-57.

5. Clark JT, Chakraborty-Chatterjee M, Hamblin M, Wyss JM, Fentie IH. Estrogen depletion differentially affects blood pressure depending on age in LongEvans rats. Endocrine. 2004;25(2):173-86.

6. Si H, Liu D. Genistein, a soy phytoestrogen, upregulates the expression of human endothelial nitric oxide synthase and lowers blood pressure in spontaneously hypertensive rats. J Nutr. 2008;138(2):297-304.

7. Dalmasso C, Maranon R, Patil C, Moulana M, Romero DG, Reckelhoff JF. 20HETE and CYP4A2 $\omega$-hydroxylase contribute to the elevated blood pressure in hyperandrogenemic female rats. Am J Physiol Renal Physiol. 2016;11:F71-7. 
8. Sartori-Valinotti JC, Venegas-Pont MR, Lamarca BB, Romero DG, Yanes LL, Racusen LC, Jones AV, Ryan MJ, Reckelhoff JF. Rosiglitazone reduces blood pressure in female Dahl salt sensitive rats. Steroids. 2010;75:794-9.

9. Mattson DL, Meister CJ, Marcelle ML. Dietary protein source determines the degree of hypertension and renal disease in the Dahl salt-sensitive rat. Hypertension. 2005;45(4):736-41.

10. Pai AV, West CA, Souza A, Cheng X, West DA Jr, Ji H, Wu X, Baylis C, Sandberg K. Salt sensitive (Rapp) rats from Envigo spontaneously develop accelerated hypertension independent of ovariectomy on a low sodium diet. Am J Physiol. Regul Integr Comp Physiol. 2018; (In press). https://doi. org/10.11152/ajpregul.00449.2017.

11. Mombaerts P, Lacomini J, Johnson RS, Herrup K, Tonegawa S, Papaioannou VE. RAG-1-deficient mice have no mature B and T lymphocytes. Cell. 1992; 68:869-77.

12. Guzik TJ, Hoch NE, Brown KA, McCann LA, Rahman A, Dikalov S, Goronzy J, Weyand C, Harrison DG. Role of the T cell in the genesis of angiotensin II induced hypertension and vascular dysfunction. J Exp Med. 2007;204:2449-60.

13. Ji H, Zheng W, Li X, Liu J, Wu X, Zhang MA, Umans JG, Hay M, Speth RC, Dunn SE, Sandberg K. Sex-specific T-cell regulation of angiotensin IIdependent hypertension. Hypertension. 2014;64:573-82.

14. Uchida HA, Kristo F, Rateri DL, Lu H, Charnigo R, Cassis LA, Daugherty A. Total lymphocyte deficiency attenuates Ang II-induced atherosclerosis in males but not abdominal aortic aneurysms in apoE deficient mice. Atherosclerosis. 2010;211:399-403.

15. Vital SA, Terao S, Nagai M, Granger DN. Mechanisms underlying the cerebral microvascular responses to angiotensin II-induced hypertension. Microcirculation. 2010;17:641-9.

16. Pollow DP, Uhrlaub J, Romero-Aleshire MJ, Sandberg K, Nikolich-Zugich J, Brooks HL, Hay M. Sex differences in T-lymphocyte tissue infiltration and development of angiotensin II hypertension. Hypertension. 2014;64:384-90.

17. Ji H, Pai AV, West CA, Wu X, Speth RC, Sandberg K. Loss of resistance to Angiotensin II-induced hypertension in the Jackson Laboratory recombination-activating gene null mouse on the C57BL/6J background. Hypertension. 2017:69:1121-7.

18. Sartori-Valinotti JC, lliescu R, Fortepiani LA, Yanes LL, Reckelhoff JF. Sex differences in oxidative stress and the impact on blood pressure control and cardiovascular disease. Clin Exp Pharmacol Physiol. 2007;34(9):938-45.

19. Gillis EE, Brinson KN, Rafikova O, Chen W, Musall JB, Harrison DG, Sullivan JC. Oxidative stress induces BH4 deficiency in male but no female SHR. Biosci Rep. 2018;38. https://doi.org/10.1042/BSR20180111.

20. Shokoji T, Nishiyama A, Fujisawa Y, Hitomi H, Kiyomoto H, Takahashi N, Kimura S, Kohno M, Abe Y. Renal sympathetic nerve responses to tempol in spontaneously hypertensive rats. Hypertension. 2003;41 (2):266-73.

21. Welch WJ, Mendonca M, Blau J, Karber A, Dennehy K, Patel K, Lao YS, José $\mathrm{PA}$, Wilcox CS. Antihypertensive response to prolonged tempol in the spontaneously hypertensive rat. Kidney Int. 2005;68(1):179-87.

22. Abais-Battad JM, Mattson DL. The influence of dietary protein on Dahl saltsensitive hypertension: a potential role for gut microbiota. Am J Physiol Regul Integr Comp Physiol. 2018;315:R907-14.

Ready to submit your research? Choose BMC and benefit from:

- fast, convenient online submission

- thorough peer review by experienced researchers in your field

- rapid publication on acceptance

- support for research data, including large and complex data types

- gold Open Access which fosters wider collaboration and increased citations

- maximum visibility for your research: over $100 \mathrm{M}$ website views per year

At BMC, research is always in progress.

Learn more biomedcentral.com/submissions 